pathologies, such as lung nodules and lung carcinoma, there may be some diagnostic and therapeutic difficulties.

\section{References}

1. Gamblin TC, Jennings GR, Christie DB, Thompson WM, Dalton ML. Ectopic thyroid. Ann Thorac Surg. 2003;75:1952-3.
2. Kaya S, Tastepe I, Kaptanoglu M, Yuksel M, Topcu S, Cetin G. Management of intrathoracic goitre. Scand J Thorac Cardiovasc Surg. 1994;28: $85-9$

3. Kawakami M, Ito K, Yoshimura K, Tanaka H. A case of mediastinal goiter. Auris Nasus Larynx. 2004;31:183-7.

4. Cohen MS, Arslan N, Dehdashti F, Doherty GM, Lairmore TC, Brunt LM, et al. Risk of malignancy in thyroid incidentalomas identified by fluorodeoxyglucosepositron emission tomography. Surgery. 2001;130:941-6.

\title{
Potential for benefits of aprotinin use to outweigh risks in patients undergoing the Ross procedure
}

\author{
Stephen Arthur Barnett, MBBS, FRACS, Matthew Liava'a, MBBS, and Peter D. Skillington, MBBS, \\ FRACS, Melbourne, Australia
}

Recent reports ${ }^{1-3}$ of adverse events related to the use of aprotinin during complex cardiac surgery and the sudden suspension of the BART (Blood conservation using antifibrinolytics: A randomized trial in a cardiac surgery population) trial because of excess mortality in the treatment arm $^{4}$ highlight the risks of death, acute renal failure, and acute coronary thrombosis during the perioperative period after treatment with this drug. Our concern is that the very real benefits of the drug in terms of reductions in bleeding, need to return to the operating room, and rate of transfusion of blood and blood products ${ }^{2}$ may be overlooked as a result of the surgical community's admirable goal to "'first do no harm.' More specifically, we suspect that there may be a subgroup of younger patients undergoing complex cardiac surgical procedures who could derive many of the previously accepted benefits with a low risk of the recently highlighted adverse events attributed to the drug.

\section{CLINICAL SUMMARY}

Between October 1992 and November 2007, a total of 250 consecutive patients underwent the Ross procedure under the care of a single surgeon (P.D.S.). ${ }^{5}$ Aprotinin was administered routinely to all patients, according to the full Hammersmith protocol. ${ }^{6}$ Mean age was 39.5 years (range 15-62 years). Mean total bypass time was 195 minutes, and mean cumulative crossclamp time was 165 minutes.

Bleeding necessitating return to the operating room occurred in 7 patients $(2.8 \%)$. Transfusion of blood or blood products was necessary in 75 patients $(30 \%)$.

\footnotetext{
From the Royal Melbourne Hospital, Parkville, Melbourne, Victoria, Australia. Received for publication Jan 25, 2008; accepted for publication Feb 13, 2008.

Address for reprints: Stephen Arthur Barnett, MBBS, FRACS, The Royal Melbourne Hospital, Cardiothoracic Surgery, Grattan St, Parkville, Melbourne, Victoria 3050,

Australia (E-mail: stephenarthurbarnett@gmail.com).

J Thorac Cardiovasc Surg 2009;138:233-4

$0022-5223 / \$ 36.00$

Copyright (c) 2009 by The American Association for Thoracic Surgery

doi:10.1016/j.jtcvs.2008.02.066
}

With regard to adverse events often described as associated with the administration of aprotinin, there were no in-hospital deaths, and acute renal impairment (defined as a doubling of preoperative creatinine level) occurred in only 4 patients $(1.6 \%)$. No patients required hemofiltration. There were no acute thromboses of any coronary artery, although 2 patients $(0.8 \%)$ did require early revision (1 during the initial time in the operating room and 1 after return to the operating room) as a result of kinking of a coronary artery (this complication was encountered solely in the early period of the series and has since been universally prevented by a modification of technique).

\section{DISCUSSION}

It is our impression that young, fit patients undergoing complex procedures, such as the Ross procedure or adult congenital cardiac surgery, involving numerous suture lines and prolonged bypass times can benefit from the use of aprotinin. Further, in this select group of patients, who often have only a small burden of atherosclerotic coronary and renovascular disease, the possible thrombotic complications of aprotinin-namely acute coronary occlusion, acute renal failure, and subsequent in-hospital mortality — may be uncommon. The well-accepted benefits of reduced blood loss and the low rates of adverse events in this select group of patients may therefore tip the balance in favor of the ongoing use of this drug.

More work is needed. A randomized trial at our institution addressing whether withholding aprotinin from patients undergoing the Ross procedure would result in reduced inhospital mortality is impossible, however, because our starting death rate is $0 \%$. Similarly, withholding aprotinin in the hope of discerning a reduction in acute renal failure from our starting level of $1.6 \%$ would require many thousands of patients. 


\section{References}

1. Mangano DT, Miao Y, Vuylsteke A, Tudor IC, Juneja R, Filipescu D, et al. Mortality associated with aprotinin during 5 years following coronary artery bypass graft surgery. JAMA. 2007;297:471-9.

2. Brown JR, Birkmeyer NJ, O'Connor GT. Meta-analysis comparing the effectiveness and adverse outcomes of antifibrinolytic agents in cardiac surgery. Circulation. 2007;115:2801-13.

3. Coleman CI, Rigali VT, Hammond J, Kluger J, Jeleniowski KW, White CM. Evaluating the safety implications of aprotinin use: The Retrospective Evaluation of Aprotinin in Cardio Thoracic Surgery (REACTS). $J$ Thorac Cardiovasc Surg. 2007; 133:1547-52.
4. US Food and Drug Administration. Early communication about an ongoing safety review: aprotinin injection (marketed as Trasylol). Center for Drug Evaluation and Research website 2007 Oct 25 [cited 2007 Dec 6]. Available from: http://www.fda. gov/cder/drug/early_comm/aprotinin.htm

5. Skillington PD, Fuller JA, Grigg LE, Yapanis AG, Porter GF. Ross procedure. Inserting the autograft using a fully supported root replacement method; techniques and results. J Heart Valve Dis. 1999;8:593-600.

6. Punjabi PP, Wyse RKH, Taylor KM. Role of aprotinin in the management of patients during and after cardiac surgery. Exp Opin Pharmacother. 2000;1: $1353-65$.

\title{
Left main compression syndrome by idiopathic pulmonary artery aneurysm caused by medial necrosis Erdheim-Gsell combined with bicuspid pulmonary valve
}

\author{
Daniel Jodocy, MD, ${ }^{\mathrm{a}}$ Guy J. Friedrich, MD,${ }^{\mathrm{a}}$ Johannes O. Bonatti, MD ${ }^{\mathrm{c}}$ Silvana Müller, MD, ${ }^{\mathrm{b}}$ \\ Guenther Laufer, MD, ${ }^{\mathrm{c}}$ Otmar Pachinger, MD, FECTS, ${ }^{\mathrm{a}}$ Patrizia Moser, MD,${ }^{\mathrm{d}}$ and \\ Gudrun M. Feuchtner, MD, ${ }^{\mathrm{b}}$ Innsbruck, Austria
}

A 71-year-old man with episodes of dyspnea presented with stress-induced anterior myocardial ischemia on myocardial single photon emission computed tomography. $\mathrm{He}$ was referred for invasive angiography, which revealed a left main coronary artery ostial catheter pressure decrease and an atypical configuration of the left main stem (Figure 1, A).

\section{CLINICAL SUMMARY}

Cardiac electrocardiogram-gated 64-slice computed tomography was performed, showing a giant pulmonary aneurysm ( $6 \mathrm{~cm}$ in diameter) (Figure 1, B-D) that significantly $(>50 \%)$ compressed the left main coronary artery during both systole and diastole. A tender bicuspid pulmonary valve without degenerative lesion (Figure 1, $D$, inlay bottom left) was found.

Pulmonary valve stenosis, pulmonary artery hypertension, and any congenital heart disease, such as atrial or ventricular septal defects, were excluded by transesophageal echocardiography. The patient underwent cardiac surgery

From the Departments of Cardiology, ${ }^{\mathrm{a}}$ Radiology, ${ }^{\mathrm{b}}$ Cardiac Surgery, ${ }^{\mathrm{c}}$ and Pathology, Innsbruck Medical University, Innsbruck, Austria.

Received for publication Jan 21, 2008; accepted for publication Feb 7, 2008.

Address for reprints: Gudrun M. Feuchtner, MD, Innsbruck Medical University, Department of Radiology II, Anichstr. 35, A-6020 Innsbruck, Austria, Europe

(E-mail: Gudrun.Feuchtner@i-med.ac.at).

J Thorac Cardiovasc Surg 2009;138:234-6

$0022-5223 / \$ 36.00$

Copyright (C) 2009 by The American Association for Thoracic Surgery

doi:10.1016/j.jtcvs.2008.02.076 under median sternotomy and cardiopulmonary bypass, including double left internal thoracic artery/left anterior descending and aortocoronary saphenous vein grafting to the circumflex artery and surgical reconstruction of the pulmonary artery aneurysm. Pathohistology of the pulmonary artery demonstrated degenerative mucoid medial necrosis Erdheim-Gsell (Figure 2). The patient was discharged on the seventh postoperative day. A 3-month follow-up was uneventful.

\section{DISCUSSION}

"Left main compression syndrome", is a rare phenomenon that is defined as a functional compression of the left main coronary artery, for example, between a dilated pulmonary artery more than $4 \mathrm{~cm}$ in diameter ${ }^{2}$ and the aortic root, or an aneurysm of the sinus of Valsalva. ${ }^{3}$

Pulmonary artery aneurysms are most commonly associated with congential heart disease, such as persistent ductus Botalli, atrial or ventricular septal defects, or tetralogy of Fallot ${ }^{4}$ or develop after pulmonary valve stenosis. Idiopathic pulmonary artery aneurysms are rare, ${ }^{4,5}$ with an estimated incidence of 1 in 13,696 in an autopsy series. ${ }^{5}$ Similar to ascending aortic aneurysm, idiopathic pulmonary aneurysm may be associated with the presence of congenital bicuspid pulmonary valves, ${ }^{6}$ a rare entity ${ }^{7}$ in the absence of congenital heart disease. However, in contrast with our case, the study by Sughimoto and colleagues ${ }^{6}$ did not find medial necrosis.

In our patient, cardiac electrocardiogram-gated multislice computed tomography was the key to clarify the atypical presentation of left main stenosis on invasive coronary 